\title{
Focus on spinal navigation
}

\author{
O. Gonschorek • V. Bühren
}

Published online: 30 March 2011

(c) Springer-Verlag 2011

Accuracy and surgical approach have always been a key issue in spine surgery. Minimal invasive techniques have been developed since the early 1990s, and were able to reduce the surgical trauma and the approach morbidity. During the same period, powerful computer systems have made real-time image processing possible. It was the initial aim of navigation to increase the accuracy of pedicle screw placement, as misplacement rates of up to $55 \%$ (thoracic spine) were reported at that time. With the development of percutaneous techniques for posterior instrumentation, the issue of C-arm techniques became even more important, and so a further positive criterion for navigation was focused on: to decrease the radiation exposure for the surgeon and his team in the operating theatre [1, 2].

There has been significant development in navigation techniques during the last 20 years. In the early stages, cables were used to connect instruments with the navigation system. The resulting problems concerning handling and sterility led to quick development steps onto wireless procedures. The registration procedure is still the cornerstone of any navigation system. CT-fluoro-matching as well as surface matching resulted in high precision, but were sometimes demanding and time-consuming. Each vertebra had to be addressed by separate matching, especially if unstable fractures had to be instrumented [2, 3].

The new intraoperative 3D-mode fluoroscopy represents a further milestone in the development of spinal surgery, allowing not only significantly simplified navigation but also detailed intraoperative $3 \mathrm{D}$ imaging. The surgeon is

O. Gonschorek $(\bowtie) \cdot$ V. Bühren

Department of Spinal Surgery, Trauma Center, BGU-Murnau, Prof. Küntscher Str. 8, 82418 Murnau, Germany

e-mail: oliver.gonschorek@bgu-murnau.de now able to collect the data directly on the patient already positioned on the operating table, and to start immediately with navigation. There is no longer a need for time-consuming matching. He is also able to immediately control the position of his instrumentation and-if necessary-to correct it before the patient leaves the operating theatre $[4,5]$.

The papers published here describe the actual techniques of intraoperative 3D imaging and spinal navigation using different tools. Anterior as well as posterior approaches are addressed, modern minimally invasive techniques included. Reviewing the literature of the past 20 years with more than 1,500 references concerning spinal navigation, an incredible fast-moving technique becomes visible. We are all looking forward to further developments.

\section{References}

1. Linhardt O, Perlick L, Luring C, Stern U, Plitz W, Grifka J. Extracorporeal single dose and radiographic dosage in imagecontrolled and fluoroscopic navigated pedicle screw implantation. Z Orthop Ihre Grenzgeb. 2005;143:175-9.

2. Nolte LP, Zamorano L, Visarius H, Berlemann U, Langlotz F, Arm $\mathrm{E}$, Schwarzenbach O. Clinical evaluation of a system for precision enhancement in spine surgery. Clin Biomech (Bristol, Avon). 1995;10:293-303.

3. Gerling J, Gosling T, Gosling A, Ortega G, Kendoff D, Citak M, Krettek C, Hufner T. Navigated pedicle screw placement: experimental comparison between CT- and 3D fluoroscopy-based techniques. Comput Aided Surg. 2008;13:157-66.

4. Tjardes T, Shafizadeh S, Rixen D, Paffrath T, Bouillon B, Steinhausen ES, Baethis H. Image-guided spine surgery: state of the art and future directions. Eur Spine. 2010;J19:25-45.

5. Wendl K, von Recum J, Wentzensen A, Grutzner PA. Iso-C(3D0assisted) navigated implantation of pedicle screws in thoracic lumbar vertebrae. Unfallchirurg. 2003;106:907-13. 